\title{
Single Phase Active Power Filter Control Under Distorted Grid Voltage Using Quasi Open-Loop Grid-Synchronization Technique
}

Biricik, Samet; Ahmed, Hafiz; Komurcugil, Hasan; Guler, Naki; Ozmen, Burcin; Benbouzid, Mohamed

\section{12th Power Electronics, Drive Systems, and Technologies Conference (PEDSTC)}

DOI:

https://doi.org/10.1109/PEDSTC52094.2021.9405949

Published: $21 / 04 / 2021$

Peer reviewed version

Cyswllt i'r cyhoeddiad / Link to publication

Dyfyniad o'r fersiwn a gyhoeddwyd / Citation for published version (APA):

Biricik, S., Ahmed, H., Komurcugil, H., Guler, N., Ozmen, B., \& Benbouzid, M. (2021). Single Phase Active Power Filter Control Under Distorted Grid Voltage Using Quasi Open-Loop GridSynchronization Technique. In 2021 12th Power Electronics, Drive Systems, and Technologies Conference (PEDSTC) (pp. 588-592). IEEE.

https://doi.org/10.1109/PEDSTC52094.2021.9405949

Hawliau Cyffredinol / General rights

Copyright and moral rights for the publications made accessible in the public portal are retained by the authors and/or other copyright owners and it is a condition of accessing publications that users recognise and abide by the legal requirements associated with these rights. study or research.

down public portal for the purpose of private

- You may not further distribute the material or use it for any profit-making activity or commercial gain

- You may freely distribute the URL identifying the publication in the public portal ?

Take down policy

If you believe that this document breaches copyright please contact us providing details, and we will remove access to the work immediately and investigate your claim. 


\title{
Single Phase Active Power Filter Control Under Distorted Grid Voltage Using Quasi Open-Loop Grid-Synchronization Technique
}

\author{
Samet Biricik*, Hafiz Ahmed ${ }^{\dagger}$, Hasan Komurcugil ${ }^{\ddagger}$, Naki Guler ${ }^{\S}$, Burcin Ozmen*, and Mohamed Benbouzid ${ }^{\uparrow}$, \\ ${ }^{*}$ Dept. of Electrical \& Electronics Engg., European University of Lefke, Lefke, Northern Cyprus, TR-10 Mersin, Turkey. \\ $\dagger$ Nuclear Futures Institute, Bangor University, United Kingdom. \\ $\ddagger$ Computer Engineering Department, Eastern Mediterranean University, Famagusta, Mersin 10, Turkey. \\ $\S$ Electrical \& Energy Department, Technical Science Vocational School, Gazi University, Ankara, Turkey. \\ ף University of Brest, UMR CNRS 6027 IRDL, France. \\ \| Logistics Engineering College, Shanghai Maritime University, 201306 Shanghai, China. \\ Email: ${ }^{\dagger}$ sbiricik,bozmen@eul.edu.tr ${ }^{\dagger}$ hafiz.h.ahme@ieee.org, ${ }^{\ddagger}$ hasan.komurcugil@emu.edu.tr, \\ $\S$ gulern@gazi.edu.tr, 9 mohamed.benbouzid@univ-brest.fr
}

\begin{abstract}
This paper proposes a quasi open-loop gridsynchronization technique-based control scheme for active power filter. The proposed filtering technique does not require any direct frequency feedback which has the advantage of unconditional stability. Based on the reference a current, a proportional integral and hysteresis band current control scheme is developed for fast and accurate tracking of the reference current by the APF's converter. Matlab/Simulink-based extensive numerical simulation studies are performed to demonstrate the robust performance of the proposed technique in distorted grid.
\end{abstract}

Index Terms-Active Power Filter, Grid-Synchronization, Adaptive Filtering.

\section{INTRODUCTION}

$\mathbf{H}$ ARMONIC distortion of grid voltage and current are a serious problem. Ever increasing presence of nonlinear loads such as power electronic converters, LED drivers, etc. together with increasing presence of distributed generation through renewable energy sources making the problem worse day by day. To overcome this problem, power quality improvement devices such as active power filter (APF) became very popular in recent time. APFs can reduce the distortion in the drawn grid current which in turn has the potential to improve the efficiency and increase the reliability of grid-connected loads. This contributed to an increasing research attention on the control of active power filter.

Control of APF has typically two parts, a) generation of the reference current, and b) tracking of the reference current by the APF controller. Reference current generation part typically employs grid synchronization technique to extract the fundamental component of the reference current. This fundamental component is then subtracted from the actual grid current to get the harmonic current. APFs controller then inject this current in opposite phase to cancel out the effect of harmonics.

978-0-7381-1197-1/21/\$31.00 @ 2021 IEEE
Numerous techniques such as phase-locked loop (PLL) [1], [2], self-tuning filter (STF) [3]-[8], second-order generalized integrator (SOGI) [9] are already proposed in the literature to generate the reference current. PLL is a preferential choice to generate the reference current due to its implementation simplicity. Tuning of PLL in the presence of unbalance grid requires additional techniques. This makes tuning of PLL a delicate choice between enhanced filtering performance versus fast dynamic response. STF and SOGI are both second-order technique where the former is frequency fixed and the latter is frequency adaptive. Large frequency fluctuation renders STF ineffective whereas it makes the tuning of SOGI gain complicated. To overcome these problems, recently open-loop techniques [6] gained some attraction. As such, in this paper, open-loop technique is considered for the reference generation purpose. The task of APF controller is to track the reference current by appropriately controlling the output of the power converter. Some popular techniques are: proportional integral (PI) [10], sliding mode control (SMC) [11], $H_{\infty}$ - control [12], fuzzy logic [13], hysteresis control [14]-[16], etc.. In the APF, there are two control function. The first task is to regulate the DC-link voltage and the second task is to maintain the desired output current. PI control is undoubtedly the most popular DC link voltage control. It is easy to tune and has a simple structure. Out of various choices, hysteresis control scheme has a simple structure, provides fast convergence and a very suitable for generating the gate signals for the power converter. This motivated the selection of hysteresis control as the current control technique in this work.

In this work, first we develop an open-loop synchronization technique to extract the distortion-free unitary sine wave which is in-phase with the grid. The DC-link voltage control loop is then used to generate the magnitude of the reference current which is multiplied with the unitary sine wave to generate the reference current. Then, hysteresis band current control scheme is used to track the reference current. The rest of 


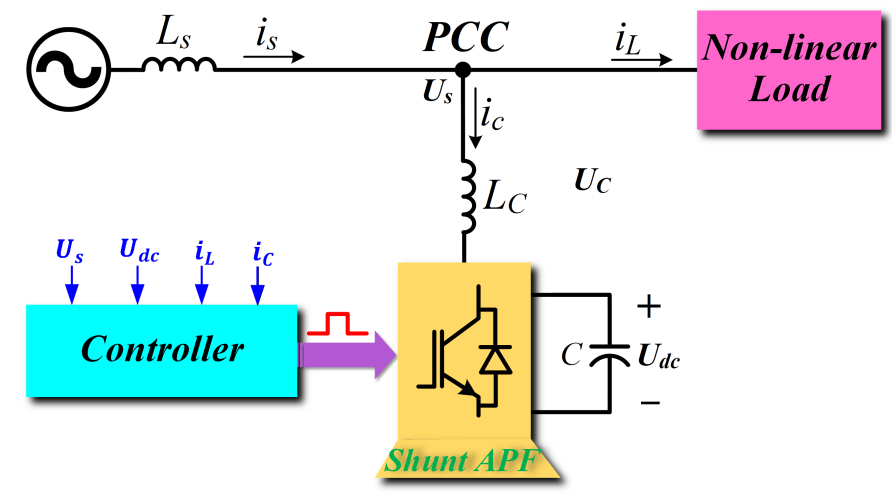

Figure 1. Block diagram of the single phase APF.

this article is organized as follows: Sec. II describes the development of the proposed method, numerical simulation results are given in Sec. III, and concluding remark are given in Sec. IV.

\section{Operation of Active Power Filter}

In this study, an inverter with a single phase H-bridge PWM and a dc-link capacitor is used. The inverter is connected to the grid via a single inductor. For the control system, current and voltage sensors were used to measure voltage on the dclink capacitor, filter current, load current and mains voltage for grid-synchronization purpose. The single line diagram of the power and control circuit used in this study is given in Figure 1.

Assuming the grid voltage is ideal, mains voltage will be defined as in (1):

$$
u_{s}(t)=U_{S} \sin (\underbrace{\omega t+\varphi}_{\theta})
$$

Since nonlinear load current contains harmonic components, it is defined as in (2):

$$
\begin{aligned}
i_{L}(t) & =\sum_{h=1}^{\infty} I_{L, h} \sin \left(h \omega t+\varphi_{h}\right), \\
& =I_{L, 1} \sin \left(\omega t+\varphi_{1}\right)+\underbrace{\sum_{h=2}^{\infty} I_{L, h} \sin \left(h \omega t+\varphi_{h}\right)}_{i_{h}},
\end{aligned}
$$

where $h$ is the harmonic order, $\varphi_{h}$ is the harmonic phase angle and $\omega$ is the angular frequency of the fundamental harmonic component. As can be seen in (2), the load current, $i_{L}$, consists of a fundamental current, $i_{L, 1}$, and harmonic currents, $i_{h}$. The two main tasks of the active power filter are to suppress the harmonic currents, $i_{h}$, and compensate reactive power, $i_{q}$. For this purpose, the voltage source inverter is controlled to generate the compensation current, $i_{c}$, which is equal to the harmonics with opposite phase, i.e.,

$$
i_{c}=-i_{h}+i_{q}
$$

In order to realize this process, the reference grid current,

$$
i_{s}^{\star}=I_{s} \sin (\theta) .
$$

must first be determined. Then, the required reference compensation current, $i_{c}^{\star}$, can be determine by subtracting the reference grid current, $i_{s}^{\star}$, from the measured load current, $i_{L}$, as given by:

$$
i_{c}^{\star}=i_{s}^{\star}-i_{L} .
$$

The use of capacitor voltage is one of the most effective methods to determine the reference current amplitude. In this method, the dc link capacitor voltage, $u_{d c}$, is measured and subtracted from the reference value, $U_{d c}^{\star}$, then the error voltage of the capacitor, $\Delta u_{d c}$, is processed by a PI algorithm as,

$$
\Delta u_{d c}=u_{d c}-U_{d c}^{\star}
$$

With the PI algorithm, grid current amplitude can be obtained as follows:

$$
I_{s}=k_{p} \Delta u_{d c}+k_{i} \int \Delta u_{d c} d t,
$$

where $k_{p}$ and $k_{i}$ are the proportional and integral gain of the DC-link PI regulator. The next most important event is that the obtained amplitude current value need to be multiplied by the grid unity sine. It becomes very difficult to obtain unity sine in case of distortion in grid voltages. To overcome this issue, linear observer-based quasi open-loop grid synchronization technique will be used. This technique will be described in the following Section.

\section{A. Generation of unity sine}

In this section, unity sine wave will be generated by extracting the instantaneous phase from the measured grid voltage $u_{s}(t)$ as given by eq. (1). For this purpose, let us consider the grid voltage and it's quadrature version as the state variables i.e.

$$
\begin{aligned}
& \zeta_{1}=u_{s}=U_{g} \sin (\theta), \\
& \zeta_{2}=u_{s}^{\perp}=U_{g} \cos (\theta) .
\end{aligned}
$$

The dynamic model of the grid voltage in terms of state variables $\zeta_{1}$ and $\zeta_{2}$ are given by:

$$
\begin{aligned}
& \dot{\zeta}=A \zeta, \\
& y=C \zeta,
\end{aligned}
$$

where $\zeta=\left[\begin{array}{ll}\zeta_{1} & \zeta_{2}\end{array}\right]^{T}$ is the state vector, $y=u_{s}$ is the output and

$$
A=\left[\begin{array}{cc}
0 & \omega \\
-\omega & 0
\end{array}\right], C=\left[\begin{array}{ll}
1 & 0
\end{array}\right] \text {. }
$$

Then, the following linear observer can be designed for (8)(9): 


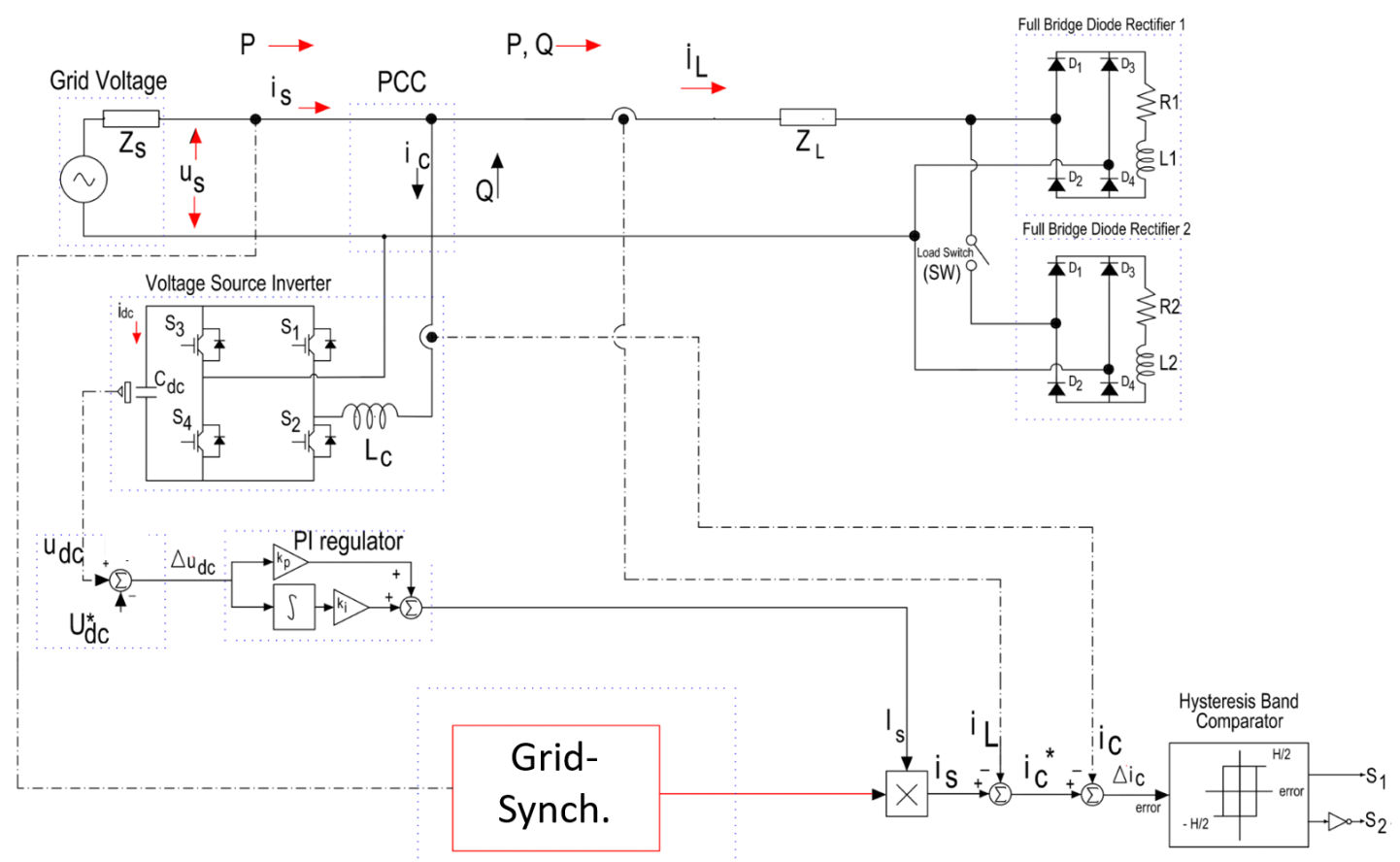

Figure 2. Overview of the proposed technique and the considered system topology.

$$
\begin{aligned}
& \dot{\hat{\zeta}}=\hat{A} \hat{\zeta}+\mathcal{L}(y-\hat{y}), \\
& \hat{y}=C \hat{\zeta},
\end{aligned}
$$

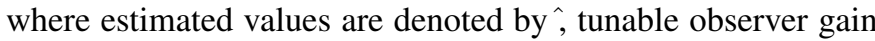
matrix is denoted by $\mathcal{L}$, and

$$
\hat{A}=\left[\begin{array}{cc}
0 & \hat{\omega} \\
-\hat{\omega} & 0
\end{array}\right] .
$$

The actual grid frequency is not known a priory. So, estimation of the unknown frequency i.e. $\hat{\omega}$ is necessary. This will be achieved by using derivative-based frequency estimation approach. For this purpose, let us normalize the states $\hat{\zeta}_{1}$ and $\hat{\zeta}_{2}$ as:

$$
\begin{aligned}
& \hat{\zeta}_{n 1}=\frac{\hat{\zeta}_{1}}{\sqrt{\hat{\zeta}_{1}^{2}+\hat{\zeta}_{2}^{2}}}=\sin (\hat{\omega} t+\hat{\varphi}), \\
& \hat{\zeta}_{n 2}=\frac{\hat{\zeta}_{2}}{\sqrt{\hat{\zeta}_{1}^{2}+\hat{\zeta}_{2}^{2}}}=\cos (\hat{\omega} t+\hat{\varphi}) .
\end{aligned}
$$

Time-derivatives of the normalized states are given by:

$$
\begin{aligned}
& \dot{\hat{\zeta}}_{n 1}=\hat{\omega} \cos (\hat{\omega} t+\hat{\varphi}), \\
& \dot{\hat{\zeta}}_{n 2}=-\hat{\omega} \sin (\hat{\omega} t+\hat{\varphi}) .
\end{aligned}
$$

Then, the unknown frequency can be found by the following relationship:

$$
\hat{\omega}=\sqrt{\dot{\hat{\zeta}}_{n 1}^{2}+\dot{\hat{\zeta}}_{n 2}^{2}} \text {. }
$$

To avoid the any fluctuations in the estimated frequency, the estimated frequency can be passed through the following leadlag filter:

$$
G(s)=\frac{\tau_{1} s+1}{\tau_{2} s+1},
$$

where filter parameters are denoted by $\tau_{1}$ and $\tau_{2}$. For a $50 \mathrm{~Hz}$ grid, $\tau_{2}=1 / 50$ and $\tau_{1}=4 / 50$ can be considered as a good value.

From the estimated states $\hat{\zeta}_{1}$ and $\hat{\zeta}_{2}$, instantaneous phase of grid voltage and correspondingly the reference current can be generated as:

$$
u_{s}=I_{s} \sin \{\underbrace{\operatorname{atan} 2\left(\frac{\hat{\zeta}_{1}}{\hat{\zeta}_{2}}\right)}_{\hat{\theta}}\},
$$

where atan 2 is the double quadrant arctanagent.

1) Tuning of the observer gain: The proposed technique has the observer gain matrix $\mathcal{L}$ to tune. For this purpose, let us consider that $\mathcal{L}=\left[\begin{array}{cc}\mathcal{L}_{1} & \mathcal{L}_{2}\end{array}\right]^{T}$. Let us consider that the desired-closed loop poles as, $p_{1,2}=-a \omega \pm i b \omega$. Then the observer gain matrix $\mathcal{L}$ can be tuned as:

$$
\begin{aligned}
\operatorname{det}\left\{s I_{2}-(A-\mathcal{L} C)\right\} & =\left(s-p_{1}\right)\left(s-p_{2}\right), \\
s^{2}+\mathcal{L}_{1} s+\omega^{2}+\mathcal{L}_{2} \omega & =s^{2}-\left(p_{1}+p_{2}\right) s+p_{1} p_{2} .
\end{aligned}
$$


By comparing the coefficients of the polynomial in both sides of eq. (19), the observer gain's can be found as:

$$
\begin{aligned}
& \mathcal{L}_{1}=-\left(p_{1}+p_{2}\right)=2 a \omega, \\
& \mathcal{L}_{2}=\frac{p_{1} p_{2}-\omega^{2}}{\omega}=\omega\left(a^{2}+b^{2}-1\right) .
\end{aligned}
$$

Let us select the desired closed-loop poles as: $-(1 / \sqrt{2}) \omega_{n}(1 \pm 1 i)$. In this case, $a=1, b=1$, and $\omega=\omega_{n}=100 \pi$ ( $50 \mathrm{~Hz}$ grid). By plugging the values of $a, b$, and $\omega$ in eqs. (20) and (21), the observer gains are found as: $\mathcal{L}_{1}=200 \pi$ and $\mathcal{L}_{2}=100 \pi$.

\section{Simulation RESUlts}

In order to verify the performance of the proposed algorithm, active power filter structure has been developed in MATLAB/Simulink. Then, the system performances is investigated for the case of distorted grid voltage and $50 \%$ load change. Grid voltage parameters are: $U_{g}=240 \mathrm{~V}, f=50 \mathrm{~Hz}$, and $L_{s}=0.7 \mathrm{mH}$. Load parameters are: $R_{1}=30 \Omega, L_{1}=80 \mathrm{mH}$, $R_{2}=40 \Omega, L_{2}=80 \mathrm{mH}$, and $L_{L}=6.8 \mathrm{mH}$. Inverter parameters are: $L_{c}=18 \mathrm{mH}, C_{d c}=800 \mu \mathrm{F}, U_{d c}=400 \mathrm{~V}$, $k_{p}=0.2$, and $k_{i}=3$. For the non-linear load in the system, RL loads fed from full bridge type rectifiers are used. Overview of the proposed control scheme and the simulation setup is given in Fig. 1. The grid voltage presented in Fig. 3 is used for the test of the proposed method under the distorted grid voltages.

The mains voltage given in Fig. 3 was used for the test of the proposed method below the distorted network voltages. Simulation results have shown that the grid voltage has a THD of $13.95 \%$. The THD of the load current (Load 1$)$ is $25.98 \%$, while the rms current is $5.45 \mathrm{~A}$; when both loads (Load1 and Load2) are connected to the grid the THD increases to $24.04 \%$ with a rms current of $12.22 \mathrm{~A}$. The proposed method has successfully achieved the reference network current. The converter current produced with the reference network current obtained has been injected into the network as shown in Fig. 4. It has been observed in Fig. 5 that the network voltage and the current drawn from the network are in the same phase and harmonic distortions on the current have decreased. As a result of this, the THD of the grid current is reduced to 3.45 $\%$ in the first load combination and it is reduced to $3.87 \%$ in the second load combination, which meets the IEEE 5191992 recommended standard. Figure 6 shows that the DC link capacitor voltage is controlled successfully under load change.

\section{CONCLUSION}

This paper has proposed an innovative filtering technique for the control of active power filter. The proposed filtering technique can generate unitary sine wave which is in-phase with the grid phase. This unitary sine wave together with a DC-link proportional integral-based controller is used to generate the reference current for the power converter. Then, a hysteresis band current controller is used for fast and accurate tracking of the reference current. The proposed technique has

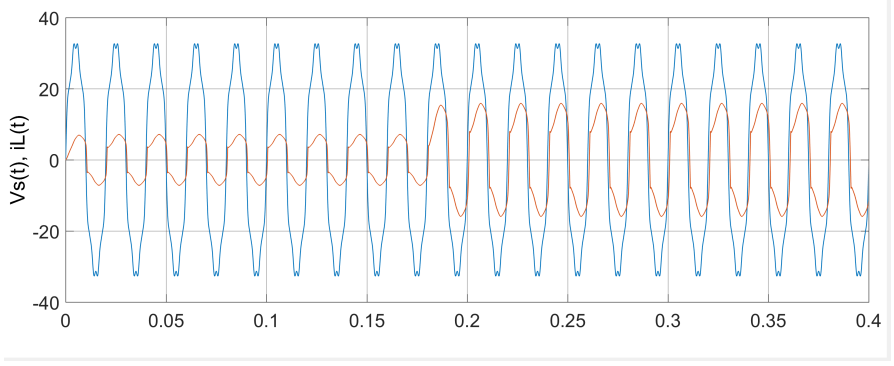

Figure 3. Grid voltage, $u_{s}$, and the load current, $i_{L}$.

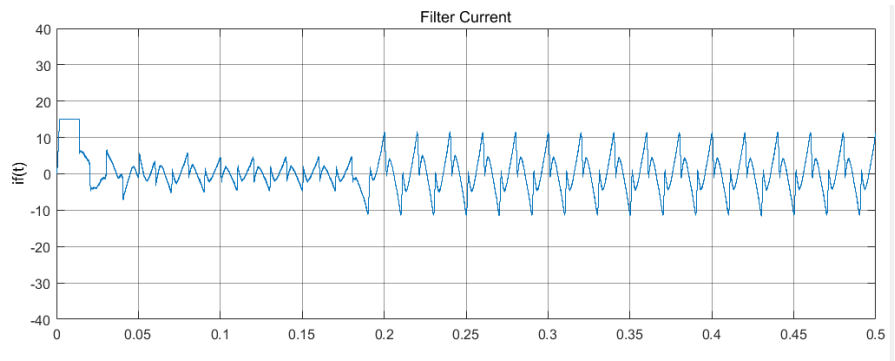

Figure 4. Converter current, $i_{c}$.

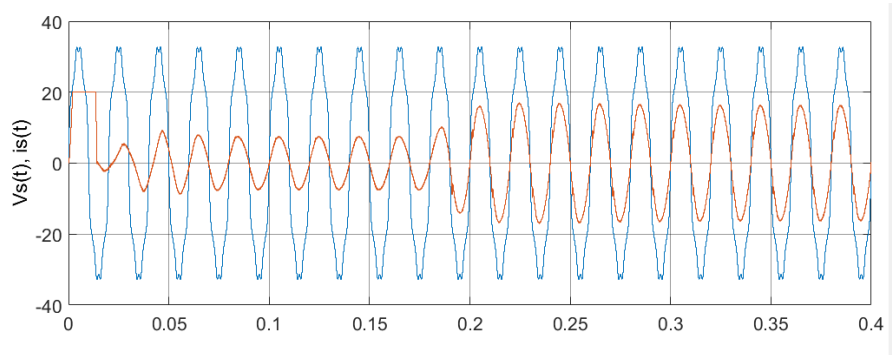

Figure 5. Grid voltage, $u_{s}$, and grid current, $i_{s}$.

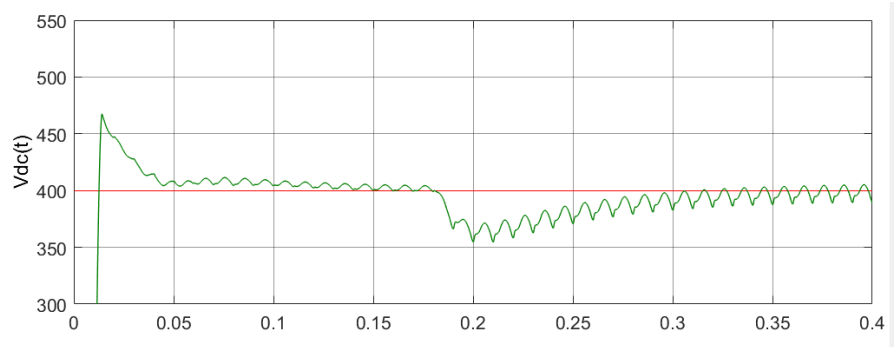

Figure 6. DC-link voltage waveform. 
drastically reduced the total harmonic distortion in the drawn grid current in a heavily distorted grid. The proposed controller is compliant with the IEEE 519-1992 standard.

\section{REFERENCES}

[1] Z. Chedjara, A. Massoum, S. Massoum, P. Wira, A. Safa, and A. Gouichiche, "A novel robust PLL algorithm applied to the control of a shunt active power filter using a self tuning filter concept," in 2018 IEEE International Conference on Industrial Technology (ICIT). IEEE, 2018, pp. 1124-1131.

[2] A. Eltarouty, M. Aboudan, S. Biricik, H. Ahmed, and M. Benbouzid, "Unbalance and disturbance rejection based phase locked loop for grid synchronization," in IECON 2020 The 46th Annual Conference of the IEEE Industrial Electronics Society. IEEE, 2020, pp. 4967-4972.

[3] M. Abdusalam, P. Poure, S. Karimi, and S. Saadate, "New digital reference current generation for shunt active power filter under distorted voltage conditions," Electric Power Systems Research, vol. 79, no. 5, pp. 759-765, 2009.

[4] S. Biricik, S. Redif, Ö. C. Özerdem, S. K. Khadem, and M. Basu, "Real-time control of shunt active power filter under distorted grid voltage and unbalanced load condition using self-tuning filter," IET Power Electronics, vol. 7, no. 7, pp. 1895-1905, 2014.

[5] S. Biricik, H. Komurcugil, T. Ngo, and M. Basu, "Operation of threelevel single-phase half-bridge npc inverter-based shunt active power filter under non-ideal grid voltage condition with sliding mode controller," in 2018 IEEE 12th International Conference on Compatibility, Power Electronics and Power Engineering (CPE-POWERENG 2018). IEEE, 2018, pp. 1-6.

[6] A. Safa, E. M. Berkouk, Y. Messlem, Z. Chedjara, and A. Gouichiche, "A pseudo open loop synchronization technique for heavily distorted grid voltage," Electric Power Systems Research, vol. 158, pp. 136-146, 2018.

[7] H. Ahmed, S. Biricik, and M. Benbouzid, "Extended self-tuning filterbased synchronization technique for unbalanced and distorted grid,' in 2020 2nd International Conference on Smart Power \& Internet Energy Systems (SPIES). IEEE, 2020, pp. 350-355.

[8] A. Safa, E. M. Berkouk, Y. Messlem, and A. Gouichiche, "A robust control algorithm for a multifunctional grid tied inverter to enhance the power quality of a microgrid under unbalanced conditions," International Journal of Electrical Power \& Energy Systems, vol. 100, pp. 253-264, 2018.

[9] A. Kherbachi, A. Chouder, A. Bendib, K. Kara, and S. Barkat, "Enhanced structure of second-order generalized integrator frequencylocked loop suitable for DC-offset rejection in single-phase systems," Electric Power Systems Research, vol. 170, pp. 348-357, 2019.

[10] M. Kashif, M. Hossain, F. Zhuo, and S. Gautam, "Design and implementation of a three-level active power filter for harmonic and reactive power compensation," Electric Power Systems Research, vol. 165, pp. 144-156, 2018.

[11] S. Ouchen, M. Benbouzid, F. Blaabjerg, A. Betka, and H. Steinhart, "Direct power control of shunt active power filter using space vector modulation based on super twisting sliding mode control,' IEEE Journal of Emerging and Selected Topics in Power Electronics, 2020.

[12] S. Ouchen, H. Steinhart, M. Benbouzid, and F. Blaabjerg, "Robust DPCSVM control strategy for shunt active power filter based on $\mathrm{H}$-infinity regulators," International Journal of Electrical Power \& Energy Systems, vol. 117, p. 105699, 2020.

[13] S. Ouchen, A. Betka, S. Abdeddaim, and A. Menadi, "Fuzzy-predictive direct power control implementation of a grid connected photovoltaic system, associated with an active power filter," Energy conversion and management, vol. 122, pp. 515-525, 2016.

[14] S. Biricik, "Grid voltage sensorless single-phase half-bridge active filter and dc bus voltage regulation," Electric Power Components and Systems, vol. 45, no. 19, pp. 2131-2140, 2017.

[15] H. Komurcugil, "Double-band hysteresis current-controlled single-phase shunt active filter for switching frequency mitigation," International Journal of Electrical Power \& Energy Systems, vol. 69, pp. 131-140, 2015.

[16] - "Hysteresis current-control strategy for single-phase half-bridge shunt active power filters," in 2013 12th International Conference on Environment and Electrical Engineering. IEEE, 2013, pp. 35-40. 